THURSDAY, OCTOBER 20, I870

\section{ON THE COLOUR OF THE LAKE OF GENEVA AND THE MEDITERRANEAN SEA}

THROUGH kindness for which I have reason to feel both proud and grateful, I have had placed in my hands two bottles of water taken from the Mediterranean Sea, off the coast of Nice. To my friend M. Soret I am also indebted for two other bottles taken from the Lake of Geneva. The friendly object in each case was to enable me to examine whether the colour of the water could in any way be connected with the scattering of light by minute foreign particles, which is found so entirely competent to produce and explain the colour of the sky. In the open Lake of Geneva, Soret himself had studied this question with considerable success, ${ }^{*}$ and my desire was to apply to it other methods of examination.

The bottles, as they reached me, and with their stoppers unmoved, were placed in succession in the convergent beam of an electric lamp. Water optically homogeneous would have transmitted the beam without revealing its track. In such water the course of the light would be no more seen than in optically pure air. The cone of light, however, which traversed the liquid, was in both cases distinctly blue, the colour from the Lake of Geneva water being especially rich and pure. Something, therefore, existed in the liquid which intercepted and scattered, in excess, the shorter waves of the beam. The longer waves were also scattered, but in proportions too scanty to render the track of the beam white. The action, in fact, was identical with that of the sky. Viewed through a Nicol's prism the light was found polarised, and the polarisation along the perpendicular to the illuminating beam was a maximum. In this direction, indeed, the polarisation was sensibly perfect. A crystal of tourmaline placed with its axis perpendicular to the beam was transparent; with its axis parallel to the beam it was opaque. By shaking the liquid larger particles could be caused to float and sparkle in the beam. The delicate blue light between these particles could be quenched by the Nicol while they were left shining in the darkened field. A concave plate of selenite, placed between the Nicol and the water, showed a system of vividly coloured rings. They were most brilliant when the vision was at right angles to the beam, just as they are most brilliant when the blue sky is regarded at right angles to the rays of the sun. In no respect could I discaver that the blue of the water was different from that of the firmament. The colour presented by the Mediterranean water was a good, sky-blue, while that presented by the Geneva water matched a sky of exceptional purity.

My interest was long ago excited by the attempts made to account for the colour of the Lake of Geneva, and continued observation in 1857 impressed me more and more with the notion that the blue was mainly that of a turbid medium. Soon afterwards I wrote thus regarding this colour :-

"Is it not probable that this action of finely divided matter may have some influence on the colour of some of the Swiss lakes - on that of Geneva for example? This

* See his letter to me, Philosophical Magazine, May, $x 869$.

VOL. II. lake is simply an expansion of the river Rhone, which rushes from the end of the Rhone glacier. Numerous other streams join the Rhone right and left during its downward course, and these feeders being almost wholly derived from glaciers, carry with them the fine matter ground by the ice from the rocks over which it has passed. Particles of all sizes must be thus ground off, and I cannot help thinking that the finest of them must remain suspended in the lake throughout its entire length. Faraday has shown that a precipitate of gold may be so fine as to require a month to sink to the bottom of a bottle five inches high; and in all probability it would require ages of calm subsidence to bring all the particles in the Lake of Geneva to its bottom. It seems certainly worthy of examination whether such particles, suspended in the water, do not contribute to that magnificent blue which has excited the admiration of all who have seen it under favourable circumstances." *

Through the observations of Saret, and through those here recorded, the surmise of thirteen years ago has become the verity of to-day.

But though in the action of small particles we have a cause demonstrably sufficient to produce the blueness referred to, it is not the only cause operative. In the Lake of Geneva we have not only the blue of scattering by small particles, but also the blue arising from true molecular absorption. Indeed, were it not for this, the light transmitted by a column of the water would be yellow, orange, or red, like the light of sunrise or sunset.t Not only then is the light mainly blue from the first moment of its reflection from the minute particles, but the less refrangible elements which always accompany the blue are still further abstracted during the transmission of the scattered light. Through the action of both these causes, scattering and absorption, the intense and exceptional blueness both of the Lake of Geneva and the Mediterranean Sea I hold completely accounted for.

During the year 1869, M. Lallemand communicated to the Paris Academy of Sciences some interesting papers on the optical phenomena exhibited by certain liquids and solids when illuminated like the actinic clouds in my experiments. I also, in I868, had examined a great number of liquids in the same manner, and a brief reference to these experiments will be found towards the end of a paper on the blue colour of the sky and the polarisation of its light, published in the Proceedings of the Royal Society for the 16 th of December, I868. M. Lallemand supposed the scattering of the light to be effected not by foreign particles but by the molecules of the liquids with which he experimented. M. Soret, on the other hand, contends against this novel view, maintaining that the scattering of the light is an affair of particles and not of molecules. While admiring the skill and learning displayed by the young French physicist, I am forced to take the side of Soret in this discussion M. Lallemand assumes a purely hypothetical cause while a true cause is at hand. $\mathrm{He}$ bases his case mainly on clear glass and distilled water. But the clearness is that observed in ordinary daylight, which is a very deceptive test. Glass exhibits the phenomena

* Glaciers of the AIps (1860), p. 26 I.

+ In fact, we hav a dichroitic action of this kind exerted by glacien water when the subsi lence is less complete than in the Lake of Geneva. 
of scattering in every degree of intensity. Exceedingly fine examples of dichroitic action on the part of this substance are to be seen in Salviati's window in St. James's Street.* By reflected light the dishes and vases there exposed exhibit a beautiful blueby transmitted light, a ruddy brownish yellow. The change of colour is very striking when, having seen the blue, a white cloud is regarded through the glass. Where the opalescence is strongest, the transmitted light, as might be expected, is most deeply tinged. From these examples, where the foreign ingredient is intentionally introduced, we may pass by insensible gradations to M. Lallemand's glass. The difference between them is but one of degree. Many of the bottles of our laboratory show substantially the same effect as the glas's of Salviati. We can hardly ascribe to molectiar action, which is constant, an effect so variable as this. It is also a significant fact that, in the case of pellucid bodies--rock salt, for example-where the powerfully cleansing force of crystallisation has come into play, M. Lallem und himself found the scattering to be nil. Under severe examination, rock salt itself would probably be found not altogether devoid of scattering power. I have examined many fine specimens of this substance, and have not succeeded in finding a piece of any size absolutely free from defect. A common form of turbidity exhibited by clear rock salt, when severely tested, resembles on a small scale "a mackerel sky." Nor have the specimens of Iceland spar that I have hitherto examined proved absolutely wanting in this internal scattering power.

In relation to this question, which is one of the first importance, the deportment of ice is exceedingly instructive. As a rule the concentrated beam may be readily tracked through ice, at least at this season of the year, when the substance shows signs of breaking up internally. In some cases the sparkle of motes, which are evidently spots of aptical rupture, reveals the track of the beam. In other cases the track appears bluish, though rarely of a uniform bluc. By causing a previously sifted beam to traverse lake ice in various directions, we are soon made aware of remarkable variations in the intensity of the scattering, and we find some places where the track of the beam wholly disappears. The convergent beam is sometimes divided by a transverse plane, one half of the cone being visible and the other invisible. In other cases the cone is divided by a plane passing from apex to base, one half shining with scattered light, and the other showing the darkness of true transparency. Now, if the scattering were molecular, it ought to occur everywhere, but it does not so occur, therefore it is not molecular. The scattering is, perhaps, in most cases due to the entanglement in the ice, when the freezing is rapid, of the ultra-microscopic particles abounding in the water. It is only by excessively slow freezing that such particles could be excluded from the ice. Purely optical ruptures of the substance itself, if minute and numerous enough, would also produce the observed effect.

The liquids which 1 examined in 1868 all showed in a greater or less degree the scattering of light, to which was added in many cases strong fluorescence. In no respect did the deportment of the non-fluorescent liquids which showed a blue track differ from that of the blue actinic clouds with which I was then occupied. I examined water from various sources and found it uniformly charged, not only with particles small enough to scatter blue light, but with far grosser particles. Tested by the concentrated beam, our ordinary drinking water presents a by no means agreeable appearance; some of the water with which London is supplied is exceedingly thick and muddy. Nor does distillation entirely remove the suspended matter. Soret vainly tried to get rid of it ; he diminished its effect, but he did not abolish it. I was favoured a few days ago with specimens of distilled water from four of the principal London laboratories. Looked at in ordinary daylight the liquid in each case would, in ordinary parlance, be pronounced "as clear as crystal," but when placed in the concentrated beam of the electric lamp, the notion of purity became simply ludicrous. No one who had not seen it would be prepared for the change produced by the concentrated illumination. There were differences of purity among the specimens, arising, doubtless, from the different modes of distillation, but to an eye capable of seeing in ordinary light what was revealed by the concentrated beam each of the specimens would appear as muddy water. I also examined a specimen of extra purity distilled from the permanganate of potash and liquefied in a glass condenser. It contained a large amount of foreign particles; not of those which scatter blue light, but grosser ones. Such must ever be the case with water distilled in the laden air of cities and collected in vessels contaminated by such air. These facts amply justify the language applied by Mr. Huxley to the statement that solutions without particles can be obtained by the processes hitherto pursued. Such a statement could only be based upon defective observation. In the number of this journal for the 17 th of March, an experiment is described in which water was obtained from the combustion of hydrogen in air, the aqueous vapour arising from the combustion being condensed by a silver surface of unimpeachable purity. In this case, though the floating particles of the air were, in the first instance, totally consumed, the water was still well la:en with foreign matter. The method of obtaining water here referred to had been resorted to by $M$. Pouchet with a view of utterly destroying all germs, and my especial object in repeating the experiment was to reveal the dangers incident to the inquiries on which M. Pouchet and others were then engaged. But the warning was unheeded. It is not for the purpose of adding to the weight of calamities, already sufficiently heavy, that I allude to this, but rather to advertise the adventurous neophyte, who may be disposed to rush into inquiries which have taxed the skill of the greatest experimenters, of some of the snares and pitfalls that lie in his way.

Royal Institution, Oct. I8 JOHN TYNDALL

\section{NICHOLSON'S MANUAL OF ZOOLOGY}

A Manual of Zoology. By H. A. Nicholson,D.Sc. Vol. Y. Invertebrate Animals. (Blackwood and Sons.)

A BOOK such as this aims at being was wanted-one A which should give a little more of systematic detail than is to be found in Professor IIuxley's "Outlines" or 